\title{
TRAINING HANDBOOK AS MEANS OF ORGANIZATION OF INTERDISCIPLINARY CONNECTIONS IN THE PROCESS OF BACHELORS TRAINING
} (C) 2016

\author{
T.M. Plekhanova, senior lecturer of the Chair of Psychology and Pedagogics \\ Samara State Technical University, Samara (Russia)
}

\begin{abstract}
This paper discusses the theoretical aspects and relevance of the interdisciplinary approach in the pedagogical process. An interdisciplinary teaching aid for public relations, developed at Psychology and Pedagogy Department of SSTU, is considered to be a form of interdisciplinary connections formation in the process of bachelors training whose major is 42.03 .01 «Advertising and public relations». This study guide is a part of the educational complex for the courses «Theory and Practice of Public Relations», «Theory and Practice of the media», «Fundamentals of communication theory» and is supposed to be used as part of their practical training. Interdisciplinary potential of this training manual is that the content and didactic units of different disciplines complement each other, forming a single integral perception of the subject. In terms of developing competencies students acquire a wide range of knowledge and skills as well as perceive a continuity and consistency between the results of the planned development of the disciplines. Implementation benefits Bachelors' 3rd year learning process and lets the students majoring in «Advertising and public relations» improve the level of training due to the accumulation of knowledge and skills from different disciplines to solve professional problems.

Keywords: interdisciplinarity; interdisciplinary studies; teaching aid; pedagogical process; bachelor; students; discipline; competence; ownership; skills; Samara State Technical University; advertising; public relations; communication.
\end{abstract}

УдК 37.015.3:177

\section{ПЕДАГОГИЧЕСКИЕ АСПЕКТЫ ДУХОВНО-ПРАКТИЧЕСКОГО ОСВОЕНИЯ ДЕЙСТВИТЕЛЬНОСТИ В МОРАЛИ} (C) 2016

О.К. Позднякова, доктор педагогических наук, профессор, член-корреспондент Российской академии образования, профессор кафедры педагогики и психологии Самарский государственный соииально-педагогический университет, Самара (Россия)

Аннотация. В статье обосновывается необходимость осмысления морали, как способа духовно-практического освоения человеком действительности, в контексте педагогического знания. Аргументируется, что духовно-практическое освоения действительности осуществляется при участии морального сознания, в механизмах функционирования которого заложены способы ориентации человека в социальном мире, в мире ценностей. Выявляется взаимосвязь морали и нравственного сознания. Мораль проявляется в поведении и поступках, в деятельности и действиях, в отношениях человека. Нравственное сознание, состоящее из представлений, взглядов, оценок, позволяет совершать выбор поступков и действий, которые реализуются в поведении и в деятельности. Представлены основания различения морали и нравственности: мораль объемлет объективное, а нравственность есть субъективное. Обосновывается, что нравственное сознание учителя, участвующее в духовно-практическом освоении действительности в морали, есть такое идеальное, которое определенным образом организует и регулирует его действия по воспитанию и обучению детей. Установлено, что духовнопрактическое освоение действительности в морали происходит на основе нравственного сознания, в котором деонтологическое и аксиологическое, оценочное и мотивационное находятся в единстве и взаимосвязи. Учитель, реализуя аксиологическое и деонтологическое через приобщение учащихся к ценностям, достигая цели образования, развивает двойную мотивацию учащихся, суть которой заключается в единстве деонтологического и аксиологического аспектов духовно-практического освоения действительности в морали.

Ключевые слова: учитель; ученик; мораль; духовно-практическое освоение действительности; моральное сознание; нравственное сознание; нравственность; ценность; педагогическая рефлексия; педагогическая деятельность; поступки; поведение; оценка; мотивация; отношения; выбор.

Содержание образования и его цели определяются как социальным, так и общекультурным контекстом жизни общества. Тот факт, что сегодня российское общество переориентируется на ценности, прежде всего нравственные, определяющие выбор человеком отдельных поступков и линии поведения в целом, показывает, что в образовании происходит переход от единообразия к многообразию. Многообразие, в отличие от единообразия, диктующего педагогу четкую последовательность этапов педагогической деятельности, и жестко задающего ее результаты, дает учителю возможность свободно, без внешней диктовки выбирать формы и методы обучения и воспитания учащихся на всех ступенях образования. Переход к многообразию от единообразия позволяет осуществить замену ролевого способа педагогической деятельности культурным способом, который наиболее отвечает ее природе.

В тоже время образование, получив свободу выбора, зачастую направляет свои ресурсы не на формирование человека нравственного, а на формирование человека успешного, который в первую очередь ориентирован не на благо, а на пользу. В образовании, приобретающем черты сферы услуг, явно про- 
слеживается отступление от личностно-ориентированной парадигмы в пользу технократической. Человек, являющийся продуктом такого образования, в своей направленности на личный успех, не задумывается о благе другого человека. Конечно же, речь не идет об абсолютно всех выпускниках образовательных учреждений. Речь идет об общей тенденции, которая сегодня прослеживается все более отчетливо. В современном мире присутствует довольно большое число образцов социализации. Это, с одной стороны, примеры бескорыстной помощи людям, развитие благотворительности, заботливого отношения к людям с особыми потребностями, с другой стороны, равнодушие к проблемам другого человека, приоритет собственных интересов в ущерб интересам других, стремление к материальному достатку любой ценой. Человек сам осуществляет выбор между жизнью нравственной и жизнью безнравственной. Можно ли помочь человеку сделать выбор в пользу нравственной жизни, жизни, достойной человека при наличии в социальной жизни разнообразных образцов социализации? Есть ли способ адаптации человека к сотканной из противоречий современной действительности, который бы (способ) предоставил бы возможность не только сохранить те нравственные ценности, что есть в обществе, но и созидать ценности, обогащать нравственные традиции?

Мы полагаем, что одним их таких способов адаптации человека к социальной реальности, к осуществлению им выбора в пользу блага, добра является духовно-практическое освоение действительности в морали. Когда мы говорим об адаптации человека к социальной реальности, то, прежде всего, подразумеваем ребенка, школьника. Формирования способности учащегося осуществлять духовно-практическое освоение действительности в морали во многом зависит и от учителя, приобщающего учащихся к ценностям, развивающего у них опыт нравственного поведения и отношений к миру, к людям и к себе. Тем самым обозначается необходимость осмысления морали в контексте педагогического знания.

Методологической основой исследования данной проблемы становится этика, которая выясняет, что представляет собой мораль.

В рамках этической науки большой вклад в исследовании проблемы морали внесли Р.Г. Апресян $[1 ; 2$; $3 ; 4]$, А.А. Гусейнов [5; 6; 7; 8; 9; 10], В.А. Блюмкин [11], В.А. Василенко [12], В. Вичев [13], О.Г. Дробницкий [14; 15], Т.С. Лапина [16], Н. Мизов [17], А.В. Разин [18; 19; 20; 21], Ю.А. Смоленцев [22], А.И. Титаренко [23], В.А. Титов [24] и другие ученые.

Мораль, являясь объектом исследования этической науки, изучается на гносеологическом, социологическом и этическом уровнях. На гносеологическом уровне мораль исследуется как форма общественного сознания, на социологическом уровне - как регулятор поведения, на этическом как особый способ духовнопрактического освоения действительности.

Существует и несколько иной подход к выделению уровней исследования морали. Согласно данному подходу, мораль как форма общественного сознания рассматривается на философском уровне; мораль с точки зрения ее взаимосвязи с различными сторо- нами и сферами материальной и духовной жизни изучается на социологическом уровне; с точки зрения внутренней специфической природы, мораль изучается на специальном частно-научном уровне - этическом уровне.

Для педагогики мораль, по утверждению Н.Д. Зотова, «выступает лишь как определенный компонент в пределах ее предметно-целевых интересов» [25, c. 49], но учет методологических и практическиконсультативных возможностей этики по отношению к педагогике позволяет определить место педагогической деятельности в духовно-практическом освоении действительности.

Анализ научной литературы показывает, что ученые единодушны относительно того, что мораль является способом духовно-практического освоения действительности.

Однако есть такой аспект при выявлении сущности духовно-практического освоения действительности, на который необходимо обратить внимание. Мы имеем в виду разграничение учеными понятий «освоение» и «отражение», то есть выяснение того, какое из данных понятий шире, а какое уже по своему значению. Существует точка зрения, согласно которой второе понятие является более глубоким и богатым по своему содержанию, чем первое. «Когда мы говорим о "способе освоения мира", - пишет М.Г. Журавков, - нас интересует - как это происходит; когда же мы говорим об отражении, нас уже интересует и что отражается и как отражается. Понятие "отражение", таким образом, богаче и глубже, чем понятие "освоение"» [26, с. 46].

Мы полагаем, что, когда речь идет о морали как о способе духовно-практического освоения действительности, тогда следует говорить именно об освоении, а не об отражении. Отражение является одной из функций морали, а потому различение понятий «освоение» и «отражение», как это сделано М.Г. Журавковым, не совсем корректно, поскольку основания, по которым осуществляется категориальный анализ понятий, различны. К другим функциям морали относятся: познавательная, оценочная, императивная, мотивационная, ориентирующая (воспитательная) функции (А.И. Титаренко [23, с. 14]); отражательная, ценностно-ориентирующая, регулятивная функции, функция формирования социального субъекта (Т.С. Лапина [16, с. 53-65]); гуманизирующая, регулятивная, ценностно-ориентирующая, познавательная, воспитательная функции (И.Л. Зеленкова и Е.В. Беляева [27, с. 97-100]).

Мораль является одной из форм духовного отношения к миру, имеющей практическую ориентацию, и ее задача - включение человека в общение, в реальные нравственные отношения. Мораль характеризует человека с точки зрения его способности жить в человеческом общежитии. «Пространство морали - отношения между людьми» $[10$, с. 20], которые всегда конкретны, а потому строятся для определенных целей.

В рамках этического подхода к исследованию морали она предстает именно как особый способ духовно-практического освоения действительности. Такое определение морали, как подчеркивает А.И. Титаренко, ориентирует исследователя на изучение «особых способов и особого характера освоения челове- 
ком действительности, которые и определяют ее своеобразие» $[23$, с. 11]. Это общее исходное определение морали указывает лишь общее направление для исследования способа освоения человеком действительности как в рамках объекта этики, так и в рамках объекта педагогики.

Обратимся к научной литературе, в которой раскрывается, каким образом происходит такое освоение действительности, каков результат, то есть что является итогом духовно-практического освоения человеком действительности, и определим место педагогической деятельности в формировании способности учащихся к духовно-практическому освоению действительности.

А.И. Титаренко при обосновании морали как способа духовно-практического освоения действительности исходит из того, что познавательные моменты подчинены регулятивной, или точнее, оценочноимперативной функции, а собственно моральные предписания не могут подменить научное знание. В таких предписаниях, которые есть только «симптом» изменений, происходящих в общественной жизни, зафиксирован особый прием ориентации человека в мире. Знание в морали закодировано в императивах требуемого поведения, оно существует в преобразованном, зашифрованном виде - через особый способ оценки и повеления [23, с. 13].

Осмысление взглядов А.И. Титаренко относительно духовно-практического способа освоения человеком действительности показывает, что такое освоение осуществляется при непосредственном участии морального сознания, в механизмах функционирования которого заложены разнообразные способы ориентации человека в социальном мире в целом и в мире ценностей в частности. Данные способы ориентации нельзя заменить научными рекомендациями. В ситуации морального выбора, когда человек определяет свои предпочтения между альтернативами, опора на них может и не дать нужного эффекта. Выбор поступков или ценностей всегда затрагивает интересы другого человека, не учитывать которые нельзя, и предусмотреть все только с помощью научных рекомендаций невозможно. Знание о морали, о ценностях и т.д. необходимо для осуществления выбора, ибо с помощью знания, в том числе и морального знания, человек осуществляет выбор и оценивает его результаты. С этих позиций становится ясным положение А.И. Титаренко о том, что познавательный момент в морали подчинен оценочно-нормативной ее функции, что в моральном требовании имеет место различие между научно-познавательным и ценностным отношениями [23, с. 15] человека к миру, к людям.

Мораль является особым способом ориентации человека в действительности. Мораль «проникает» в нравственное сознание человека, которое уже содержит в себе этические, моральные знания, на базе которых у человека формируются представления, взгляды, идеи. Моральные представления, взгляды, идеи человека состоят из элементов знаний, которые необходимы для оценки действий и поступков, взглядов и идеалов. Содержание оценки у различных людей различно. Человек оценивает избирательно, поскольку предметом его оценки, осуществляемой на основе того знания, которое содержится в его созна- нии, является то, что имеет для него значение. Однако в ситуации морального выбора он может оценивать и то, что, возможно, в данный момент его жизнедеятельности не имеет для него значения. Такое оценивание побуждает сознание человека к поиску ценностей, которые, находясь в объективной ценностной системе, станут основанием и критерием для оценивания. Как подчеркивает А.И. Титаренко: «Для морального сознания характерны напряженный поиск ценностно-нормативного смысла поступков и отношений людей, резкое усиление этого смысла и на этом основании - оценка социальных взаимосвязей в обществе» [23, с. 16].

Осмысление идеи А.И. Титаренко о том, что моральное сознание осуществляет поиск ценностнонормативных смыслов, дает нам основание утверждать, во-первых, что в моральном сознании начинают «сопрягаться» аксиологическое и деонтологическое. Во-вторых, оценка выполняет функцию ориентации человека в мире ценностей и норм, которые он выбирает избирательно. Мораль избирательна, как избирательны наши отношения к миру, к людям, к их действиям и поступкам. Моральное сознание человека может и не обращать внимания на то, что для человека не представляет значения. В-третьих, избирательный выбор нужных человеку ориентиров возможен при условии сочетания оценки и адекватных ей критериев, в качестве которых выступают ценности и нормы. «Сочетание нормативности, императивности, оценочности, мотивационности, - пишут Л.М. Архангельский и Т. Джафарли, - особенность только морального сознания» [28, с. 154]. Такое сочетание нормативности, императивности, оценочности, мотивационности означает, что моральное сознание оперирует не просто знаниями, не просто категориями морали, но целостными «смысловыми образованиями», которые задают эскиз будущего.

Эскиз будущего, равно как и категории, которыми оперирует моральное сознание, могут, с одной стороны, выражать нормативные требования. С другой стороны, выступать в качестве ориентиров, перспектив личностного развития. Мораль, проникая в сознание человека, как пишет А.А. Гусейнов, «существует не как состояние, а как вектор сознательной жизни. Она обретает реальность как долженствование. Долженствование нельзя противопоставлять бытию... Долженствование и есть специфический способ существования морали... Мораль потому и существует в форме долженствования, что ни в какой другой форме не может обрести реальность - цель, на которую нацелена мораль» $[10$, с. 30$]$.

Долженствование является одной из характеристик морали как особого способа духовно-практического освоения действительности. Нормативность присуща и нравственному сознанию человека. Означает ли это, что мораль сводится к нравственному сознанию. Нет, не означает. Однако нравственное сознание играет заметную, существенную роль в духовно-практическом освоении действительности. Чем более развито нравственное сознание, тем богаче сфера долженствования, оценочности, мотивационности, императивности. Развитость нравственного сознания человека во многом зависит от морали, суще- 
ствующей в обществе. Более того, мораль включена в систему социальных отношений, она фиксирует такие отношения, а нравственное сознание отдельного человека не в состоянии отразить всю систему социальных отношений, равно как и всю систему императивов, долженствований. Нравственное сознание избирательно относится к императивам, к ценностям, находящимся в объективной ценностной системе общества, к долженствованиям. Мораль, как и нравственное сознание, естественно, охватывает и сферу должного, и сферу сущего, но содержание такого «охвата» данных сфер различно. Мораль проявляется, реализуется в поведении и поступках, в деятельности и действиях, в отношениях человека. Нравственное сознание, состоящее из представлений, взглядов, оценок и т.д., «участвует» в выборе поступков и действий, которые реализуются в поведении и в деятельности. Нравственное сознание «участвует» в выборе ценностей, а природа морали ценностная. Нравственное сознание «видит», «обращает внимание» на ценности, что, однако, не означает, что данные ценности будут «схвачены» им. Необходимо создавать условия для перехода ценностей из объективной ценностной системы в субъективную ценностную систему человека. Это, на наш взгляд, является одним из оснований различения морали и нравственности. Мораль объемлет объективное, а нравственность есть субъективное. Другим основанием для различения морали и нравственности может быть рефлексия. Нравственность - это есть рефлексия человека на себя. Про мораль мы так сказать не можем.

А.А. Гусейнов обосновывает непосредственную задачу морали, состоящую в организации реального общения между людьми. Мораль как форма духовного отношения к миру, как отмечает ученый, всегда практически ориентирована [10, с. 21]. Мораль как способ практической ориентации поведения, согласно А.А. Гусейнову, представляя собой определенное ценностное отношение к миру, является выражением активности человеческого сознания. При этом нравственные взгляды и представления даны в единстве с практическими отношениями, а основным средством освоения действительности является нравственное требование [10, с. 24].

Особый интерес, с точки зрения рассмотрения морали как предмета педагогической рефлексии, представляют положения А.А. Гусейнова о том, что нравственное сознание, участвующее в духовно-практическом освоении действительности, является особым случаем целеполагающей деятельности [10, с. 24]. С данной позиции нравственное сознание учителя есть такое идеальное, которое определенным образом организует и регулирует его действия по воспитанию и обучению детей. «Выходя» при этом за пределы внешней заданности, нравственное сознание учителя «перемещается» в реальный мир общения, что является условием разрешения противоречий целеполагания. Выходя за пределы своей субъективности, учитель в своем сознании самореализуется, а областью его оценок и самооценок становится долженствование, но не требование.

Дальнейшее развитие научных представлений о морали как способе духовно-практического освоения действительности мы находим у Ю.М. Смоленцева, который, опираясь на положения А.И. Титаренко о морали и нравственном сознании, подчеркивает важность исследования морали в контексте единства должного и сущего применительно к современной действительности. На пути реализации возможностей, заключенных в этическом подходе к изучению морали, как подчеркивает Ю.М. Смоленцев, возникает ряд теоретико-методологических проблем. Такими проблемами являются, во-первых, проблема ценностного содержания морали, которую с позиции должного и сущего в полной мере решить не представляется возможным. Во-вторых, проблемы, связанные с изучением механизмов поведения человека, которые также только с позиции должного и сущего решить нельзя. Новое, что вносит Ю.А. Смоленцев в понимание морали как особого способа духовно-практического освоения действительности, заключается, вопервых, в выделении ценностных аспектов морали; во-вторых, в обосновании того, что деятельность человека, в которой проявляется должное и сущее в их единстве, включает в себя не только поступки, но и «реальные образования морального сознания - оценки, нормы, идеалы, чувства, установки» [22, с. 18-19].

Вопросы, связанные с раскрытием сущности духовно-практического освоения действительности и его соотношением с моральным сознанием человека, нашли свое обоснование в работах А.В. Разина, который подчеркивает, что духовно-практическое освоение действительности всегда осуществляется на основе сознания, позволяющего, во-первых, расширить возможности предвосхищения состояний действительности, ее опережающего отражения. Во-вторых, дающего возможность конструировать действительность, которая создается за счет активности сознания [21, с. 378$]$.

Не анализируя в полном объеме идеи А.В. Разина о специфике духовно-практического освоения действительности [21, с. 380-396], остановимся на таких положениях ученого, которые вписываются в объект педагогической науки.

Первое, что следует учитывать при выявлении места педагогической деятельности в духовно-практическом освоении действительности, состоит в том, что мораль выражает важнейшую сторону создаваемой реальности, так как в ней в результате коллективной работы общественного сознания вырабатываются такие понятия, которые позволяют людям сплотиться, обрести общий смысл бытия. Второе - сложности мотивации, которые объясняются тем, что человек отражает лишь ограниченный круг социальный отношений, о чем речь шла выше. Третье - сознание не только отражает реальность, но и конструирует ее. Происходящее посредством морального сознания приспособление человека к существующей реальности сопровождается возникновением новых отношений, утверждением новых, практически целесообразных способов жизни. В этом, по мнению А.В. Разина, и заключается суть процесса духовно-практического освоения действительности: «Важнейшим итогом духовно-практического освоения действительности является утверждение в общественной жизни определенных социальных норм» [18, с. 108]. 
Осмысление представленных выше положений А.В. Разина о сущности духовно-практического освоения человеком действительности, осуществляемого на основе сознания, показывает, что главной функцией в этом процессе является регулятивная функция морали, которую, однако, не следует абсолютизировать. Отметим, что А.В. Разин, раскрывая сущность духовно-практического освоения действительности, ведет речь об общественном сознании, а не о нравственном сознании человека. Это, с нашей точки зрения, и приводит к тому, что вне поля зрения ученого при раскрытии сущности духовно-практического освоения действительности остаются ценностные аспекты морали. А.В. Разин обращается к проблеме ценностей только тогда, когда раскрывает соотношение между нормой и ценностью, обосновывает нормативную и ценностную стороны в общественном требовании, выявляет содержание ценностного отношения человека к миру, к людям и к себе.

Осмысление идей ученых относительно сущности духовно-практического освоения человеком действительности позволяет нам выделить такие стороны данного способа освоения действительности, которые представляют интерес для педагогической науки, что и послужит отправным моментом для определения места педагогической деятельности в контексте морали как особого способа духовно-практического освоения действительности.

В результате анализа научной литературы, посвященной проблеме духовно-практического освоения действительности, мы пришли к выводу, что такое освоение происходит на основе нравственного сознания, в котором деонтологическое и аксиологическое, оценочное и мотивационное находятся в единстве и взаимосвязи. Педагогическая деятельность, центрированная на ученика, упорядочивает ценностную субъективную систему ученика, нормализует его взаимодействие с миром и с людьми. Реализация учителем аксиологического и деонтологического, осуществляемая через приобщение учащихся к ценностям, через организацию ценностно-ориентационной деятельности, в процессе которой данные ценности осваиваются и становятся основанием моральных норм, заключает в себе возможность при достижении цели образования развивать двойную мотивацию учащихся. Суть такой мотивации заключается в единстве деонтологического и аксиологического аспектов духовно-практического освоения действительности в морали.

\section{СПИСОК ЛИТЕРАТУРЫ:}

1. Апресян Р.Г. Восхождение к морали. М.: Прогресс, $1991.297 \mathrm{c}$.

2. Апресян Р.Г. Идея морали и базовые нормативно-этические программы. М.: ИФРАН, 1995. 348 с.

3. Апресян Р.Г. Прикладная этика и общая теория морали // Ведомости прикладной этики. 2012. № 40. C. $84-95$.

4. Арсеньев А.С. Философские основания понимания личности. М.: Академия, 2001. 592 с.

5. Гусейнов А.А. Идея абсолютного в морали. М.: РАГС, 2004. $29 \mathrm{c}$.
6. Гусейнов А.А. Как возможна абсолютная мораль? // Ведомости прикладной этики. 2012. № 40. C. $96-115$.

7. Гусейнов А.А. Кто может быть экспертом в вопросах морали? // Ведомости прикладной этики. 2012. № 41. C. $122-134$.

8. Гусейнов А.А. Мораль как прорыв к бытию // Философские науки. 2014. № 4. С. 7-10.

9. Гусейнов А.А. Сослагательное наклонение морали // Вопросы философии. 2001. № 5. С. 3-32.

10. Гусейнов А.А., Апресян Р.Г. Этика. М.: Гардарики, $1998.472 \mathrm{c}$.

11. Блюмкин В.А. Мир моральных ценностей. М.: Знание, 1981. 64 с.

12. Василенко В.А. Мораль и общественная практика. М.: МГУ, 1983. 176 с.

13. Вичев В. Мораль и социальная психика. М.: Прогресс, 1978. 360 с.

14. Дробницкий О.Г. К вопросу о специфике морали // Предмет и система этики. М.: Институт философии АН СССР; София: Институт философии БАН, 1973. C. 179-207.

15. Дробницкий О.Г. Понятие морали. М.: Наука, 1974. $388 \mathrm{c}$.

16. Лапина Т.С. Социальные функции морали // Мораль и этическая теория. М.: Наука, 1974. С. 50105.

17. Мизов Н. О системе научного познания морали // Предмет и система этика. М.: Институт философии АН СССР; София: Институт философии БАН, 1973. C. $132-151$.

18. Разин А.В. Духовно-практическое освоение действительности в морали и праве // Lex Russica. 2015. № 4. C. 104-112.

19. Разин А.В. О возможности научного обоснования морали // Вестник Московского университета. Сер. 7. Философия. 2001. № 1. С. 48-61.

20. Разин А.В. Онтологические основы морали в сознании современного общества // Вестник Московского университета. Сер. 7. Философия. 2004. № 4. C. 58-79.

21. Разин А.В. Этика. М.: Академический проект, $2003.624 \mathrm{c}$.

22. Смоленцев Ю.А. Мораль и нравы: диалектика взаимодействия. М.: МГУ, 1989. 200 с.

23. Титаренко А.И. Специфика и структура морали // Мораль и этическая теория. М.: Наука, 1974. C. 7-49.

24. Титов В.А. Мораль познающая. М.: Знание, $1988.64 \mathrm{c}$.

25. Зотов Н.Д. Личность как субъект нравственной активности: природа и становление. Томск: Изд-во Томского ун-та, 1984. $248 \mathrm{c.}$

26. Журавков М.Г. О необходимости подразделения этики на общую философскую теорию и частные дисциплины // Предмет и система этики. М.: Институт философии АН СССР; София: Институт философии БАН, 1973. С. 37-68.

27. Зеленкова И.Л., Беляева Е.В. Этика: учебное пособие и практикум. Минск: ТетраСистемс, 1997. 368 с.

28. Архангельский Л.М. Джафарли Т. Этические категории // Предмет и система этики. М.: Институт философии АН СССР; София: Институт философии БАН, 1973. С. 152-178. 


\section{PEDAGOGICAL ASPECTS OF SPIRITUAL AND PRACTICAL ASSIMILATION OF REALITY TO MORALITY} (C) 2016

O.K. Pozdnyakova, doctor of pedagogical sciences, professor, corresponding member of Russian Academy of Education, professor of the Pedagogy and Psychology Department Samara State University of Social Sciences and Education, Samara (Russia)

Abstract. The paper considers the necessity of thinking about morality as a means of spiritual and practical development of human reality in the context of pedagogical knowledge. It is argued that the spiritual and practical assimilation of reality is carried out with the participation of the moral consciousness and the methods of social orientation in the human world, the world of values are in its functioning mechanisms. The author reveals the relationship of morality and moral consciousness. Morality can be found in behavior and actions, in activities and actions, in human relationships. The moral consciousness, consisting of ideas, opinions, estimates, allows you to make the choice of actions and activities that are implemented in behavior and activities. The author differentiates morality and ethics: morality is objective and ethics are subjective. It is proved that the moral consciousness of the teachers involved in the spiritual and practical assimilation of reality to morality is an ideal that in a certain way organizes and regulates his or her actions on education and training of children. It has been established that the spiritual and the practical reality in the development of morality takes place on the basis of moral consciousness in which deontological and axiological, evaluative and motivational are in unity and relationships. The teacher realizing axiological and deontological through familiarizing students to the values, achieving the purpose of education, develops the double motivation of students, the essence of which lies in the unity of the deontological and axiological aspects of the spiritual and practical assimilation of reality to morality.

Keywords: teacher; student; moral; spiritual and practical mastery of reality; moral consciousness; moral consciousness; morality; value; pedagogical reflection; educational activities; actions; behavior; evaluation; motivation; attitudes; choices.

УДК 378.14

\section{МОДЕЛЬ СИСТЕМЫ ФОРМИРОВАНИЯ У СТУДЕНТОВ ПРОФЕССИОНАЛЬНОЙ ЭКСПЕРИМЕНТАЛЬНО-ИССЛЕДОВАТЕЛЬСКОЙ КОМПЕТЕНЦИИ}

\section{(C) 2016}

Д.В. Попов, старший преподаватель кафедры общей физики и физики нефтегазового производства Самарский государственный технический университет, Самара (Россия)

Аннотация. В статье представлены результаты исследования по разработке и реализации педагогической системы формирования у студентов технического университета профессиональных экспериментально-исследовательских компетенций в процессе перманентного выполнения ими комплекса лабораторных работ. Проблема и ее решение рассматриваются на примере подготовки специалистов по специальности «Физические процессы в нефтегазовом производстве». Показана роль и место лабораторного исследовательского эксперимента в компетентностной парадигме профессиональной подготовки специалистов по физическим процессам нефтегазового производства.

Дана авторская трактовка понятия «профессиональная экспериментально-исследовательская компетенция», определены ее функциональные и содержательные компоненты.

В статье представлена теоретическая модель педагогической системы формирования у студентов профессиональных экспериментально-исследовательских компетенций в процессе выполнения лабораторных исследовательских экспериментов, которая является алгоритмом и системным навигатором для разработчиков и пользователей аналогичных систем.

Разработаны дескрипторы функциональных и содержательных компонентов (когнитивного, операционального, деятельностного), которые используются в качестве критериев оценки уровней сформированности у студентов профессиональной экспериментально-исследовательской компетенции.

Рассматривается содержание и структура информационно-дидактической базы формирования профессиональной экспериментально-исследовательской компетенции, доминирующее место в которой занимает комплекс лабораторных работ по физике и физическим процессам нефтегазового производства.

Приведены результаты проведенного констатирующего и формирующего экспериментов по выявлению исходного и итогового уравнений сформированности у студентов экспериментальной и контрольной групп, свидетельствующие о целесообразности и высокой эффективности использования инновационной компетентностно-модульной технологии проведения лабораторных экспериментально-исследовательских работ.

Ключевые слова: профессиональная экспериментально-исследовательская компетенция; нефтегазовое производство; система формирования профессиональной компетенции; компетентностно-модульная технология; информационно-дидактическая база; лабораторно-экспериментальная работа; критерий уровня сформированности. 